\title{
3D-QSAR Study of Indol-2-yl Ethanones Derivatives as Novel Indoleamine 2,3-Dioxygenase (IDO) Inhibitors
}

\author{
KAMLENDRA S. BHADORIYA*1, SHAILESH V. JAIN ${ }^{1}$, SANJAYKUMAR B. BARI ${ }^{2}$, \\ MANISH L. CHAVHAN ${ }^{1}$, AND KULDEEP R. VISPUTE ${ }^{1}$ \\ ${ }^{1}$ R. C. Patel Institute of Pharmaceutical Education and Research, Shirpur, Dist- Dhule, \\ Maharashtra 425405, India. \\ ${ }^{2}$ Department of Pharmaceutical Chemistry, R. C. Patel Institute of Pharmaceutical Education \\ and Research, Shirpur, Dist- Dhule, Maharashtra 425405, India. \\ kamlendra.bhadoriya@gmail.com
}

Received 20 August 2011; Accepted 4 October 2011

\begin{abstract}
D-QSAR approach using $k$ NN-MFA was applied to a series of Indol-2-yl ethanones derivatives as novel IDO inhibitors. For the purpose, 22 compounds were used to develop models. To elucidate the structural properties required for IDO inhibitory activity, we report here $k$-nearest neighbor molecular field analysis ( $k$ NN-MFA)- based 3D-QSAR model for Indol-2-yl ethanones derivatives as novel IDO inhibitors. Overall model classification accuracy was $76.27 \%\left(\mathrm{q}^{2}=0.7627\right.$, representing internal validation $)$ in training set and $79.35 \%$ (pred_r ${ }^{2}=0.7935$, representing external validation) in test set using sphere exclusion and forward as a method of data selection and variable selection, respectively. Contour maps using this approach showed that hydrophobic and steric effects dominantly determine binding affinities. The information rendered by $3 \mathrm{D}-\mathrm{QSAR}$ model may lead to a better understanding of structural requirements of IDO inhibitors and can help in the design of novel potent molecules.
\end{abstract}

Keywords: 3D-QSAR, $k$ NN-MFA, IDO inhibitors, Forward Stepwise Variable Selection, Indol-2-yl ethanones derivatives.

\section{Introduction}

Human indoleamine 2,3-dioxygenase (IDO) (MW 47,000) has been implicated as a key participant in the development of senile cataracts and in a variety of immunological roles, many of which have implications for treatment of cancer $^{1-4}$. It is known that IDO is over expressed in a variety of diseases, including cancer, neurodegenerative disorders (e.g., Alzheimer's diseases), age-related cataract, and HIV encephalitis ${ }^{5}$. Although IDO is critical 
to host defense against pathogens, it is now clear that this enzyme plays multiple roles in the immune system ${ }^{6}$.

IDO is a ubiquitously expressed enzyme, encoded by the INDO gene, which catalyzes the initial and rate limiting step in the degradation of tryptophan along a pathway which can lead to the biosynthesis of $\mathrm{NAD}^{+}$(nicotinamide adenine dinucleotide). IDO does not, however, handle dietary catabolism of tryptophan, which is instead the role of the structurally unrelated liver-specific enzyme tryptophan dioxygenase (TDO2), nor does it appear to be critical for maintaining $\mathrm{NAD}^{+}$levels ${ }^{7,8}$. In order for IDO to be catalytically active, it is essential to maintain the heme iron ion in the ferrous $\left(\mathrm{Fe}^{2+}\right)$ state. As the enzyme is susceptible to autoxidation ${ }^{8,9}$.

IDO is a monomeric extrahepatic cytosolic heme dioxygenase that catalyzes the addition of oxygen across the $\mathrm{C}-2 / \mathrm{C}-3$ bond of the indole ring of tryptophan ${ }^{10}$. The oxidative cleavage of the 2,3 double bond in the indole moiety, resulting in the production of $\mathrm{N}$ formylkynurenine. Heme iron that exists in the active site of IDO is active as its ferrous $\left(\mathrm{Fe}^{2+}\right)$ form, whereas the ferric $\left(\mathrm{Fe}^{3+}\right)$ form is inactive ${ }^{9}$. Under healthy conditions, IDO is expressed modestly in various tissues but it is highly induced by bacterial and viral infection. This induction is mediated mainly by IFN- $\gamma$ and results in increased Trp degradation along the Kyn pathway. The Trp degradation induced by IDO during infection plays a role in the defense mechanism against the infectious pathogens ${ }^{11}$.

Three dimensional quantitative structure activity relationship (3D-QSAR) is widely used tool to identify the steric, electrostatic and hydrophobic structural requirements of various drugs acting via receptor modulation for exerting biological activity. Thus, 3D-QSAR is valuable molecular modeling tool for drug design. By the application of 3D-QSAR models, the number of compounds that need to be synthesized by a medicinal chemist can be reduced greatly. Thus, the time and cost of drug discovery and development can also be reduced $^{12,13}$.

\section{Experimental Work}

\section{Hardware and software}

3D-QSAR study was performed using the Molecular Design Suite (VLife MDS software package, version 3.5; from VLife Sciences, Pune, India) ${ }^{14}$ user interface implemented on Acer PC with a Pentium IV processor and Windows XP operating system.

\section{D-QSAR Study}

\section{Biological activity data set}

A data set of 22 molecules of reported series for IDO inhibitory activities have been taken for $3 \mathrm{D}-\mathrm{QSAR}$ study ${ }^{8}$. IDO inhibitory activity was expressed as $\mathrm{pIC}_{50}$. The structures of all compounds were constructed in Chem sketch version $12.0^{15}$. All structures are cleaned and 3D optimized. All structures were optimized using Merck Molecular Force Field (MMFF) with distance dependent dielectric function and energy gradient of $0.001 \mathrm{kcal} / \mathrm{mol} \AA$. The conformers for all structures are generated and selected the low energy conformer for each compound and used for further study.

Molecular modeling for $3 D-Q S A R$

3D-QSAR studies were performed using a Sphere Exclusion Method selected training set of 18 compounds for generating 3D-QSAR models and a test set of 4 compounds for validating the quality of the models. In vitro inhibitory concentrations $\left(\mathrm{IC}_{50}\right)$ of the molecules were converted into corresponding $\mathrm{pIC}_{50}$ values and used as dependent variables in $3 \mathrm{D}-\mathrm{QSAR}$ calculations (Table 1). 
Table 1. Structure of training and test sets of compounds along with observed and predicted<smiles>Cn1cc(CC(N)C(=O)O)c2ccccc21</smiles>

1MT<smiles></smiles>

$7 a-7 u, 12 a$<smiles>O=C(Cc1ccccn1)c1cc2ccccc2[nH]1</smiles>

8 a<smiles>C[C@H](C(=O)c1cc2ccccc2[nH]1)c1cccnc1</smiles>

$7 \mathrm{v}$<smiles>O=C(Nc1cccnc1)c1cc2ccccc2[nH]1</smiles>

21

\begin{tabular}{lcccc}
\hline Compd & $\mathrm{R}$ & $\mathrm{R}_{1}$ & Observed $\mathrm{pIC}_{50}$ & Predicted $\mathrm{pIC}_{50}$ \\
\hline $1 \mathrm{MT}$ & - & - & 4 & 4.08 \\
$7 \mathrm{a}$ & $\mathrm{H}$ & $\mathrm{H}$ & 4.19 & 4.06 \\
$7 \mathrm{c}$ & $4-\mathrm{F}$ & $\mathrm{H}$ & 3.82 & 4.03 \\
$7 \mathrm{~d}$ & $4-\mathrm{MeO}$ & $\mathrm{H}$ & 4.24 & 4.37 \\
$7 \mathrm{e}$ & $4-\mathrm{OH}$ & $\mathrm{H}$ & 4.08 & 4.2 \\
$7 \mathrm{f}^{*}$ & $5-\mathrm{F}$ & $\mathrm{H}$ & 4.44 & 4.37 \\
$7 \mathrm{~g} *$ & $5-\mathrm{Cl}$ & $\mathrm{H}$ & 4.61 & 4.74 \\
$7 \mathrm{~h}$ & $5-\mathrm{Br}$ & $\mathrm{H}$ & 4.74 & 4.88 \\
$7 \mathrm{i}$ & $5-\mathrm{Me}$ & $\mathrm{H}$ & 4.06 & 4.19 \\
$7 \mathrm{j}$ & $5-\mathrm{OMe}$ & $\mathrm{H}$ & 4.31 & 4.09 \\
71 & $5-\mathrm{Ph}$ & $\mathrm{H}$ & 4.02 & 3.86 \\
$7 \mathrm{~m}$ & $5-\mathrm{CF}{ }_{3} 0$ & $\mathrm{H}$ & 4.88 & 4.74 \\
$7 \mathrm{o}$ & $5-\mathrm{OH}$ & $\mathrm{H}$ & 4.43 & 4.31 \\
$7 \mathrm{p}$ & $6-\mathrm{F}$ & $\mathrm{H}$ & 4.37 & 4.35 \\
$7 \mathrm{q}$ & $7-\mathrm{MeO}$ & $\mathrm{H}$ & 4.09 & 4.31 \\
$7 \mathrm{~s}$ & $4-\mathrm{OH}, 5-\mathrm{MeO}$ & $\mathrm{H}$ & 4.2 & 4.08 \\
$7 \mathrm{t}$ & $4,6-\mathrm{DiCl}$ & $\mathrm{H}$ & 3.86 & 3.85 \\
$7 \mathrm{u}$ & $4,6-\mathrm{DiMeO}$ & $\mathrm{H}$ & 4.35 & 4.37 \\
$12 \mathrm{a} *$ & $\mathrm{H}$ & $\mathrm{Me}$ & 4.47 & 4.24 \\
$8 \mathrm{a}^{*}$ & - & - & 4.43 & 4.43 \\
$7 \mathrm{v}$ & - & - & 3.85 & 3.86 \\
21 & - & - & 4.03 & 4.19 \\
\hline
\end{tabular}

*Compounds belonging to test set.

This approach resulted in selection of compounds nos. 12a, 7f, $7 \mathrm{~g}$ and $8 \mathrm{a}$ as the test set and the remaining 18 compounds as the training set.

Selection of molecules in the training set and test is a key and important feature of any QSAR model. Therefore the care was taken in such a way that biological activities of all compounds in test lie within the maximum and minimum value range of biological activities of training set of compounds. The UniColumn Statistics of test and training sets further reflected the correct selection of test and training sets. A Uni-Column statistics for training 
set and test set were generated to check correctness of selection criteria for trainings and test set molecules (Table 2).

Table 2. Unicolumn statistics of the training and test sets for QSAR models.

\begin{tabular}{ccccccc}
\hline Data set & $\begin{array}{c}\text { Column } \\
\text { name }\end{array}$ & Average & Max. & Min. & SD & Sum \\
\hline Training & $\mathrm{pIC}_{50}$ & 4.1956 & 4.8800 & 3.8200 & 0.2871 & 75.5200 \\
Test & $\mathrm{pIC}_{50}$ & 4.4875 & 4.6100 & 4.4300 & 0.0834 & 17.9500 \\
\hline
\end{tabular}

\section{Alignment procedure}

Alignment of all 22 compounds was done using the template-based alignment by using the most active molecule $(7 \mathrm{~m})$ as reference and indole as a basic template (Figure1) in MDS; the aligned structures were used for the study. These aligned conformations were used to generate the predictive QSAR models.

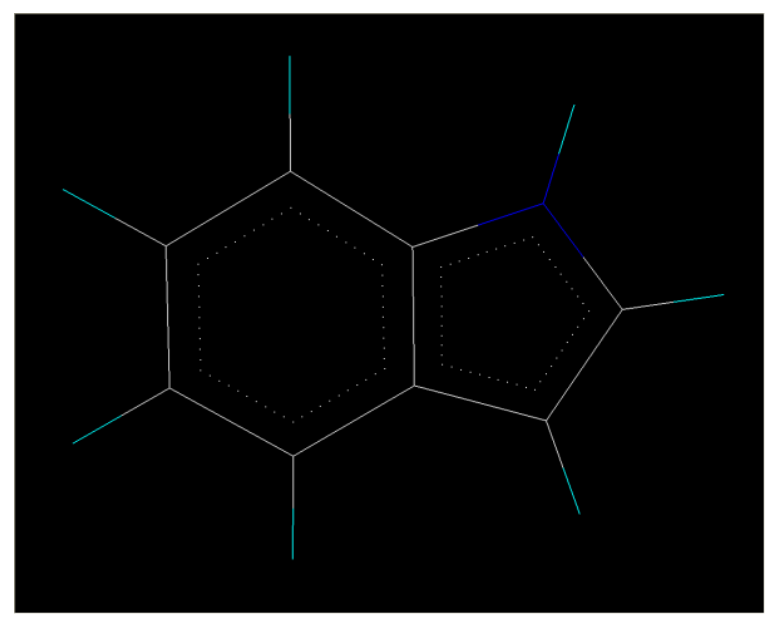

Figure 1 Basic template for alignment.

\section{Calculation of descriptors}

Using Tripos force field ${ }^{16}$ and Gasteiger and Marsili charge type, ${ }^{17}$ electrostatic, steric and hydrophobic field descriptors were calculated. This resulted in calculation of 4290 field descriptors (1430 for each electrostatic, steric \& hydrophobic) for all the compounds in separate columns. QSAR analysis was performed after removal of all the invariable columns, as they do not contribute to the QSAR.

3D-QSAR studies were carried out by $k \mathrm{NN}$ method using Forward Stepwise Variable Selection as variable selection method.

\section{Results and discussion}

For 3D-QSAR $k$ NN-MFA of Indol-2-yl ethanones derivatives with reported activities as novel IDO inhibitors were prepared. Several 3D-QSAR models were generated using 
stepwise variable selection method resulted several statistically significant models, of which the corresponding best model is reported herein. 3D-QSAR model was selected based on the value of statistical parameters \& the best $k$ NN MFA 3D-QSAR model with 18 training set compounds have a $\mathrm{q}^{2}=0.76$ and pred_ $\mathrm{r}^{2}=0.79$ (Table 3).

Table 3. Statistical results of 3D-QSAR model generated by forward stepwise variable selection $k$ NN MFA method for indol-2-yl ethanones derivatives.

\begin{tabular}{|c|c|c|}
\hline \multirow[t]{2}{*}{ Sr. No. } & Statistical parameter & Results \\
\hline & & 3D-QSAR by $k \mathrm{NN}$ \\
\hline 1 & $\mathrm{r}^{2}$ & - \\
\hline 2 & $r^{2} \mathrm{se}$ & - \\
\hline 3 & $q^{2}$ & 0.76 \\
\hline 4 & $q^{2}$ se & 0.14 \\
\hline 5 & pred $r^{2}$ & 0.79 \\
\hline 6 & pred $r^{2} \mathrm{se}$ & 0.16 \\
\hline 7 & F-Test & - \\
\hline 8 & $\mathrm{~N}$ & 18 \\
\hline 9 & $\mathrm{k}$ nearest neighbor & 2 \\
\hline 10 & Degree of freedom & 15 \\
\hline 11 & Contributing descriptors & $\begin{array}{l}\text { 1. H_1348 }(0.255712,0.27929) \\
\text { 2. } S-1366(-0.009408,-0.003614)\end{array}$ \\
\hline
\end{tabular}

The observed, predicted activities for IDO inhibitory activities against IDO enzyme of both training \& test sets molecules are given in Table 1 . The plots of observed versus predicted activity of both training \& test sets molecules helped in cross-validation of $k$ NN-MFA QSAR model are depicted in Figure 2.
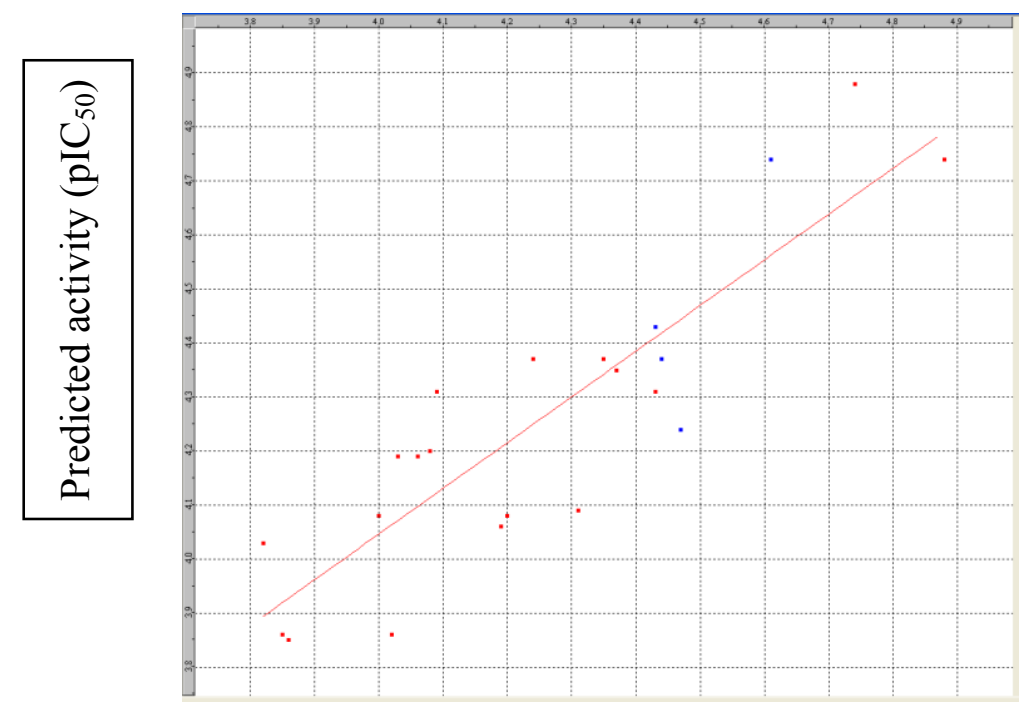

\section{Observed activity $\left(\mathrm{pIC}_{50}\right)$}

Figure 2 Comparison of observed activity versus predicted activity for training set $\&$ test set compounds according to 3D-QSAR model by $k$ NN MFA. 


\section{Interpretation of kNN-MFA model}

In 3D-QSAR studies, 3D data points generated indole pharmacophore were used to optimize the hydrophobic and steric requirements for the IDO inhibitory activity. The range of property values in the generated data points helped for the design of NCEs. These ranges were based on the variation of the field values at the chosen points using the most active molecule \& its nearest neighbor set. The points generated in SW-kNN MFA 3D-QSAR model are H $1348(0.255712,0.27929)$ and $\mathrm{S} 1366(-0.009408,-0.003614)$ that is hydrophobic and steric interaction fields at lattice points 1348 \& 1366 respectively (Figure 3 ). These points suggested the significance and requirement of hydrophobic and steric properties as mentioned in the ranges in parenthesis for SAR \& maximum biological activities of indol-2-yl ethanones analogues.

Positive values in field descriptor indicated the requirement of positive hydrophobic potential for enhancing the biological activity of indol-2-yl ethanones analogues. Therefore more hydrophobic substituents such as $-\mathrm{C}_{6} \mathrm{H}_{11},-\mathrm{C}_{6} \mathrm{H}_{5},-\mathrm{C}\left(\mathrm{CH}_{3}\right)_{3},-\mathrm{CF}_{3},-\mathrm{CH}_{3}$ etc. were preferred at the position of generated data point H_1348 around indol-2-yl ethanones. Similarly, the less negative values of steric descriptors suggested the requirement of less steric group such as Thiazole-1-yl, 1,2,4-Triazole, Pyridine etc. at the position of generated data point S_1366 (-0.009408, -0.003614) around indol-2-yl ethanones pharmacophore for maximum activity.

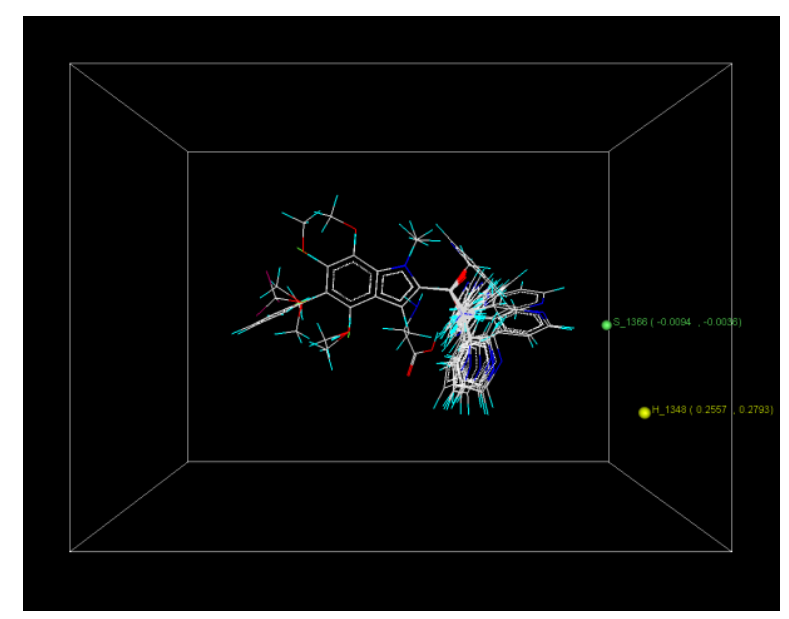

Figure 3 Stereoview of the molecular rectangular field grid around the superposed molecular units of Indol-2-yl ethanones series of compounds using SW- $k$ NN MFA method.

It can be seen that the $k \mathrm{NN}$ MFA model obtained by using forward stepwise variable selection method shows that hydrophobic and steric interactions play major role in determining biological activity.

\section{Conclusions}

In the present study, 3D-QSAR model of Indol-2-yl ethanones was developed using Vlife MDS software. The location and range of function values at the field points selected by model (Figure 3) provide the clues for the design of new molecules thus giving insight on structural requirements for designing more potent analogues as IDO inhibitors. The 3D- 
QSAR study has shown that more hydrophobic substituents and less steric groups would be favourable for the IDO inhibitory activity. This model is expected to provide a good alternative to predict the biological activity prior to synthesis of other analogues as potent and novel IDO inhibitors.

\section{References}

1. Takikawa O, Littlejohn T, Jamie J F, Walker M J, Truscott R J, Adv Exp Med Biol., 1999, 467, 241.

2. Wirleitner B, NeurauterG, Schrocksnadel K, Frick B, Fuchs D, Curr Med Chem.,2003,10,1581.

3. Muller A J, Duhadaway J B, Donover P S, Sutanto-Ward E, Prendergast G C, Nat Med., $2005, \mathbf{1 1}, 312$.

4. Dolusic E, Larrieu P, Blanc S, Sapunaric F, Pouyez J, Moineaux L, Colette D, Stroobant V, Pilotte L, Colau D, Ferain T, Fraser G, Galleni M, Frere J M, Masereel B, Eynde B V, Wouters J, Frederick R, Eur J Med Chem., 2011, 46, 3058-3065.

5. Matsuno K, Takai K, Isaka Y, Unno Y, Sato M, Takikawa O, Asai A, Bio Med Chem Lett., 2010, 20, 5126-5129.

6. Jung I D, Lee J S, Lee C M, Noh K T, Jeong Y I, Park W S, Chun S H, Jeong S K, Park J W, Son K H, Heo D R, Lee M G, Shin Y K, Kim H W, Yun C H, Park Y M, Biochem Pharm., 2010, 80, 491-505.

7. Muller A J, Metz R, Prendergast G C, Inter Congress Ser., 2007, 1304, 250-261.

8. Dolusic E, Larrieu P, Blanc S, Sapunaric F, Norberg B, Moineaux L, Colette D, Stroobant V, Pilotte L, Colau D, Ferain T, Fraser G, Galeni M, Frere J M, Masereel B, Eynde B V, Wouters J, Frederick R, Bioorg Med Chem., 2011, 19, 1550-1561.

9. Nakashima H, Uto Y, Nakata E, Nagasawa H, Ikkyu K, Hiraoka N, Nakashima K, Sasaki Y, Sugimoto H, Shiro Y, Hashimoto T, Okamoto Y, Asakawa Y, Hori H, Bioorg Med Chem., 2008, 16, 8661-8669.

10. John S, Thangapandian S, Sakkiah S, Lee K W, Eur J Med Chem., 2010, 45, 40044012.

11. Takikawa O, Inter Congress Ser., 2007, 1304, 290-297.

12. Gaurav A, Yadav M R, Giridhar R, Gautam V, Singh R, Med Chem Res., 2010, DOI 10.1007/s00044-010-9306-5.

13. Jain S V, Bhadoriya K S, Bari S B, Med Chem Res., 2011, DOI 10.1007/s00044-0119681-6.

14. VLife MDS 3.5, Molecular Design Suite, Vlife Sciences Technologies Pvt. Ltd., Pune, India, 2004. (www.vlifesciences.com).

15. Chem sketch version 12.0 .

16. Clark M, Cramer R D III, Van O N, J Comput Chem., 1989, 10, 982-1012.

17. Gasteiger J, Marsili M, Tetrahedron, 1980, 36, 3219-3228. 


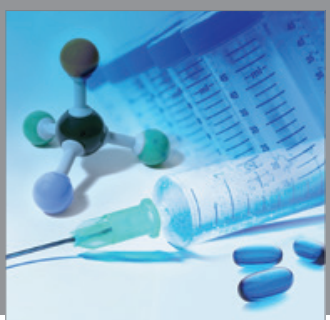

International Journal of

Medicinal Chemistry

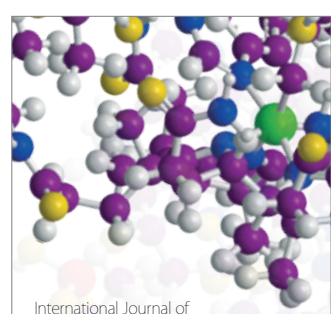

Carbohydrate Chemistry

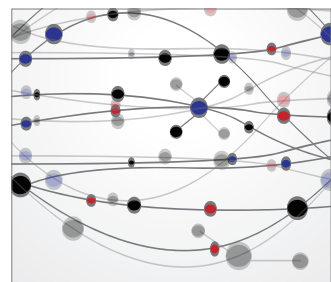

The Scientific World Journal
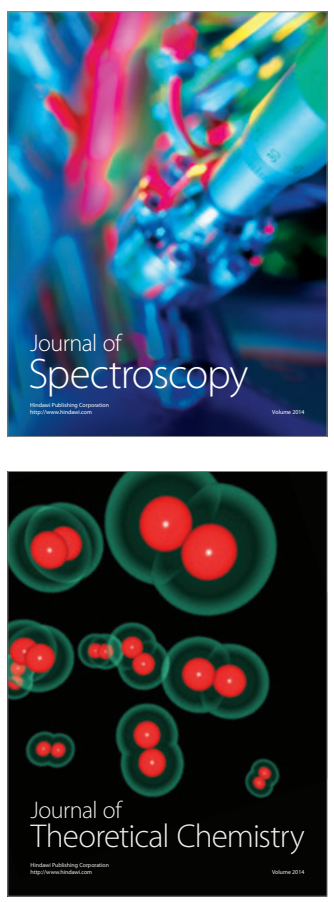
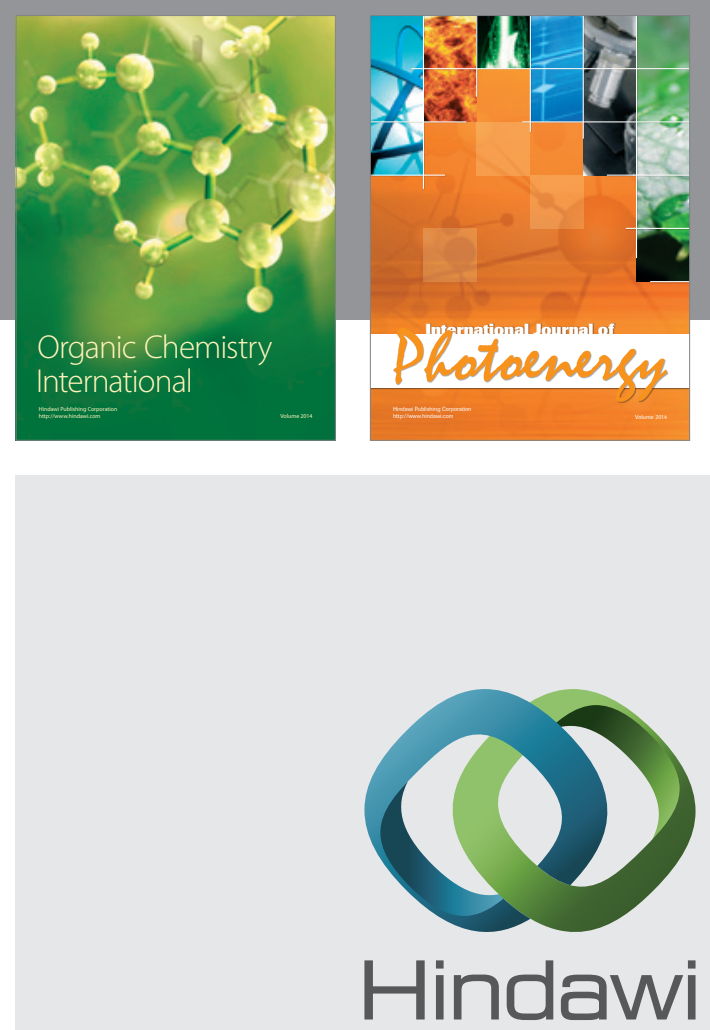

Submit your manuscripts at

http://www.hindawi.com
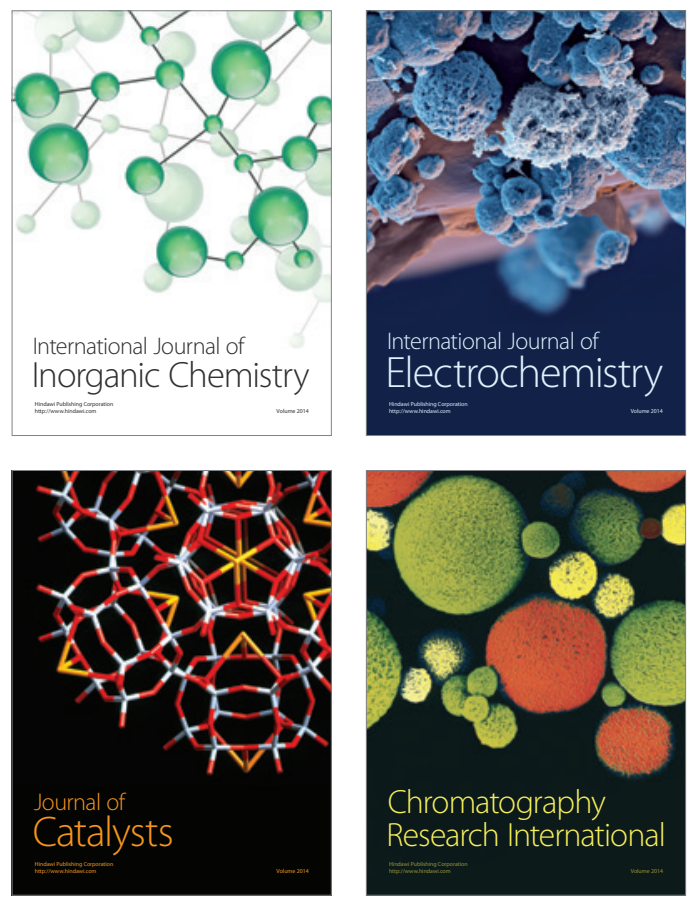
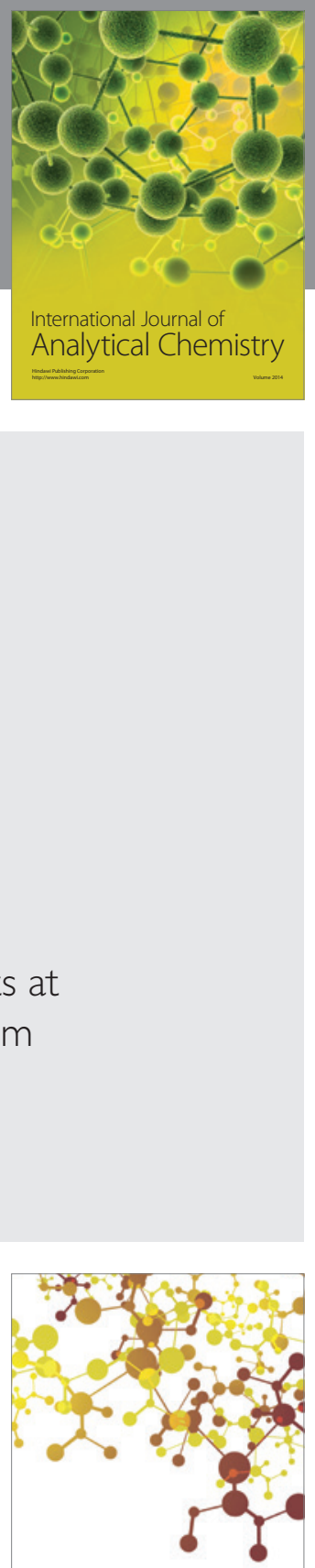

Journal of

Applied Chemistry
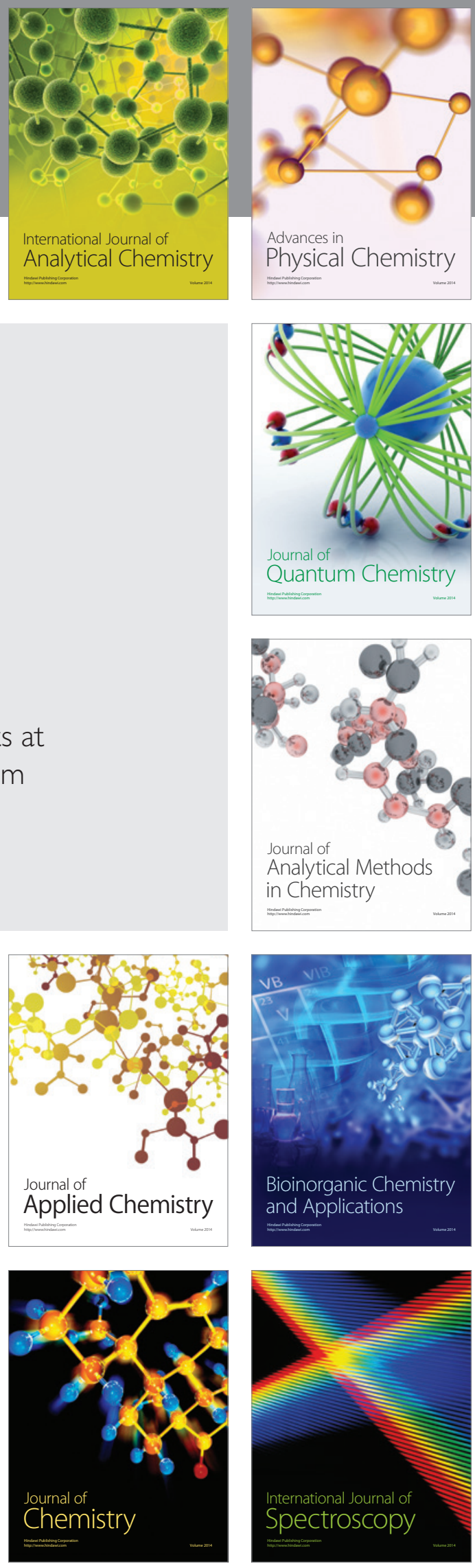